\title{
The influence of concrete substrate moisture condition on the tensile pull-off strength of protective coatings
}

\author{
Sean $\mathrm{Kay}^{1 *}$ and Hans Beushausen ${ }^{2}$ \\ ${ }^{1}$ Spec-con Engineering, Midrand, South Africa \\ ${ }^{2}$ University of Cape Town, Cape Town, South Africa
}

\begin{abstract}
A range of different surface coatings are available for the protection of concrete surfaces, typically aimed at reducing the ingress of deleterious substances into the concrete and providing adequate aesthetic appeal on patch-repaired elements. The coating systems are usually of high material quality and perform well when applied and maintained correctly. The long-term success of protective surface coatings is largely a function of application procedures. In particular, coating durability with regards to bond strength and crack resistance is dependent on the preparation of the concrete substrate prior to coating application. This research gives insight into the effects a sound, clean and profiled concrete substrate that is subjected to different moisture conditions has on coating bond strength. The influence of three different methods to precondition concrete substrates on the tensile pull-off strength of two commercial coatings, applied to substrate concrete with various strengths was investigated. The moisture condition was found to have a significant influence on the pull-off strength of the coatings, higher degrees of substrate saturation typically resulting in higher strengths. Similarly, with increasing substrate moisture content, the failure mode increasingly shifted towards substrate cohesion failure.
\end{abstract}

\section{Introduction}

Surface coatings are often considered the easiest and most economic option for durability enhancement and protection of concrete structures subjected to aggressive environments. The requirements for the coating will influence the type of coating used on the concrete surface as well as the associated costs involved. Bassi and Roy [1] state that concrete coatings can provide a surface capable of the following characteristics: decorative enhancements, improved cleanability, reduced dust adhesion, enhanced slip and abrasion resistance, reinforcement corrosion protection, and chemical resistance to name a few. They further state that in order to achieve adequate surface coating performance, the concrete (substrate) characteristics must be carefully considered prior to application of the coating. Improper/inadequate substrate surface preparation is the leading cause of concrete surface coating failure and this has brought about the importance of investigating the surface for contaminants, defects, internal contaminants, bond breakers, and potential moisture vapour transmission problems prior to any application. It is therefore critical to the performance of the coating that the substrate be sound, clean, free from any surface defects and surface-dry in order to establish an adequate mechanical bond [2]. The coating manufacturer will usually provide guidelines on substrate surface preparation requirements and any additional needs prior to application of their products.
Coatings can generally be divided into two generic categories, those either being of an organic or of an inorganic type [1, 3]. Before commencing with any surface coating material/system application, the surface of the deteriorated (or new) concrete must be prepared to varying specifications, as per product requirements. It is therefore important that concrete removal and concrete surface preparation be done precisely and thoroughly checked before any material is applied. High-pressure water jetting, sometimes with some sand introduced, is typically the most suitable method to achieve most surface bonding requirements but other methods may be used to achieve the desired surface profile under various site conditions and/or constraints. Bond strength is majorly influenced by surface cleanliness, the presence of a laitance layer on the substrate, micro-cracking in surface region of substrate, compaction of patch repairs as well as curing methods used. American Standards for concrete surface cleaning and for the practice of abrading concrete include ASTM D 4258 [4] and ASTM D 4259 [5] respectively. The former standard provides methods for surface cleaning of concrete in order to remove grease, dirt, and loose material prior to coating application. The methods include broom cleaning, vacuum cleaning, air blast cleaning, water cleaning, detergent water cleaning, and steam cleaning. The latter standard provides a practice that is intended to alter the surface profile of the concrete as well as to remove foreign materials and weak surface laitance. The practice includes abrasive blasting (wet or dry), mechanical

\footnotetext{
Corresponding author: sean@spec-con.co.za
} 
abrading, water blasting, as well as similar procedures that will change the concrete surface profile.

Bond strength between concrete substrate and coating is usually determined with tensile pull-off tests, as discussed further below. The quality of the concrete and that of the coating is important when analysing pulloff test results. According to ACI and BRE [3], it is specified that minimum values for adhesion of greater than $1 \mathrm{~N} / \mathrm{mm}^{2}$ for a test on vertical surfaces and greater than $1.5 \mathrm{~N} / \mathrm{mm}^{2}$ on horizontal top surfaces should be achieved. Values that are less than $1 \mathrm{~N} / \mathrm{mm}^{2}$ should however not be rejected if the failure had occurred within the body of the concrete given the concrete is of an acceptable quality upon further investigation. Failure between the concrete and coating or failure between successive layers of the coating is considered unacceptable. Failure between the concrete and coating is generally an indication of inadequate surface preparation. Typical tensile bond failure modes during pull-off testing are shown in Figure 1.

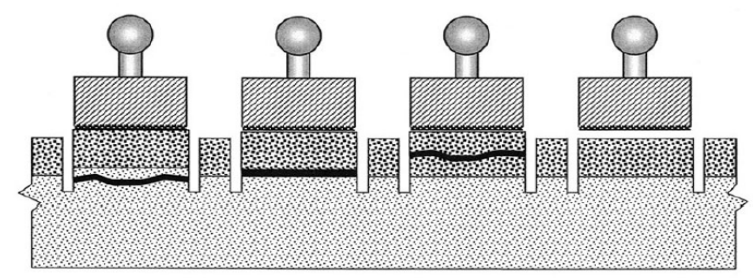

Figure 1: Tensile bond testing and typical failure modes (from left to right: failure in substrate, failure at the interface, failure in the coating, failure between dolly and coating) [6]

Research on the moisture related affects on surface coating adhesion has been done by Benn [7]. The main findings of the research were that no preferred method of surface preparation is provided in literature. However, it is clear that a general substrate requirement is for it to be sound, clean and free from contaminants. It is also evident that moisture within and surrounding the concrete substrate is an important aspect when considering the longevity of the coating to be applied. In most cases where a cementitious type coating is to be used, a saturated but surface dry substrate condition is the minimum acceptable criteria prior to coating application.

The effects of pre-wetting the concrete substrate prior to coating application needs to be investigated in order to confirm whether or not this condition does indeed positively influence the adhesion of the coating to the substrate. The aim of this research was therefore to establish if there is a relationship between substrate moisture condition and the effective bond strength created by modified cementitious based (inorganic) concrete coatings, provided the concrete substrate was sound and free from contamination prior to coating application. In addition, the effect on substrate compressive strength on pull-off strengths was evaluated.

\section{Experimental details}

\subsection{Substrate concrete}

Concrete slabs were produced as substrate specimens for coating application. Two different concrete substrates were produced, as summarized in Table 1.

Table 1: Substrate concrete mix composition and 28-day compressive strength

\begin{tabular}{|l|l|l|}
\hline \multirow{2}{*}{} & \multicolumn{2}{|c|}{ Mass $\left(\mathrm{kg} / \mathrm{m}^{3}\right)$} \\
\cline { 2 - 3 } & Substrate 1 & \multicolumn{1}{c|}{ Substrate 2 } \\
\hline w/b ratio & 0.70 & 0.55 \\
\hline water & 185 & 185 \\
\hline CEMII/A-L 52.5N & 264 & 336 \\
\hline 13mm greywacke & 1050 & 1050 \\
\hline Philippi dune sand & 906 & 845 \\
\hline fc, 28 days & 30.2 & 40.2 \\
\hline
\end{tabular}

The surfaces of all hardened substrate specimens were wet sandblasted to receive a high quality surface profile. The Concrete Repair Manual [3] describes the effective profile achieved through the use of abrasive blasting techniques. The achievable profiles are between CSP2 and CSP5, with CSP3 being the most commonly achieved profile. The CSP 3 profile was therefore aimed at, with aggregate exposure at the surface, as this profile is considered suitable for most types of coatings. The substrate surfaces prior to and after sandblasting are shown in Figures 2 and 3.

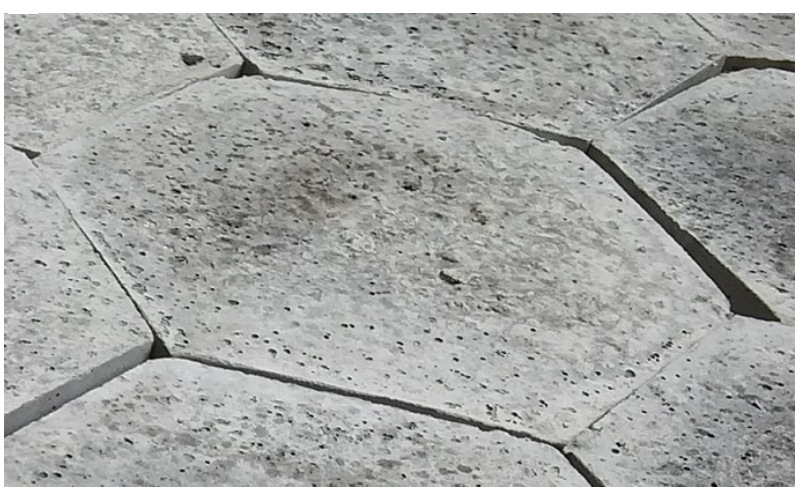

Figure 2: Substrate surface prior to sandblasting

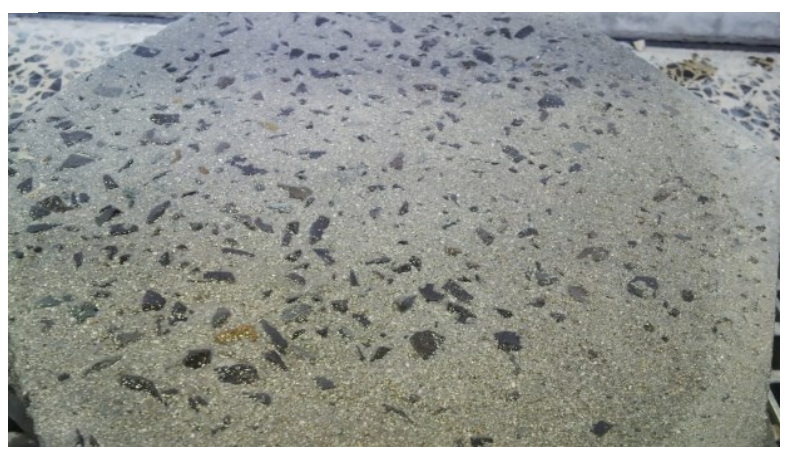

Figure 3: Substrate surface after sandblasting 
Three different substrate moisture conditions were created as follows:

- Moisture Condition 1 (MC1): Oven-dry. For this condition the specimens were oven dried for 36 hours at 50 degrees Celsius and then left to cool for 24 hours prior to any coating application. The temperature and humidity were controlled at 23 degrees Celsius and $50 \%$, respectively.

- Moisture Condition 2 (MC2): Dried under ambient conditions. Specimens were removed from the curing tanks and left to dry under controlled conditions (23 degrees Celsius, $50 \% \mathrm{RH}$ ) for 24 hours prior to any coating application.

- Moisture Condition 3 (MC3): Saturated surface dry. The substrates were prepared according to the requirements provided by the coating material supplier. The surface was pre-wetted and saturated surface-dry prior to coating application.

\subsection{Surface coatings}

The following coating types were used in this research:

- Coating 1: Sikagard, 720 Epochem. Three-part, epoxy modified cementitious material for the levelling and finishing of concrete surfaces, recommended layer thickness $0.5-3 \mathrm{~mm}$. The achieved thickness was 3 - $4 \mathrm{~mm}$.

- Coating 2: SikaTop Armatec, 110 Epochem. Cementitious, epoxy resin compensated three-component coating material with corrosion inhibitor, recommended for use as bonding primer and reinforcement corrosion protection, layer thickness 1 $\mathrm{mm}$. The thickness achieved was $1-1.5$ $\mathrm{mm}$.

The coatings were mixed and applied according to the specifications of the supplier [8], with the exception that the substrate moisture condition was varied as discussed earlier. The specifications for installation of the 2 coating types stipulate a saturated, surface dry substrate surface condition to be provided. The coatings were allowed to fully cure prior to pull-off testing.

\subsection{Pull-off testing}

The tensile pull-off strength of the coated samples was determined following the recommendations provided in Vicroads [9]. The test areas were isolated by coring about $10 \mathrm{~mm}$ deep into the composite specimens, leaving a circular test area with a diameter of about $52 \mathrm{~mm}$. A circular steel test dolly with a diameter of $50 \mathrm{~mm}$ was glued to the coating using a 2-component high strength, fast hardening adhesive (Figure 4). The apparatus used was a Proceq DY-216 automated pull-off tester, which has a working range of 1.6 to $16 \mathrm{kN}$ tensile force and 0.81 to $8.1 \mathrm{MPa}$ stress range using a test disc diameter of $50 \mathrm{~mm}$ (Figure 5). Per test parameter, 3 pull-off tests were performed and the mean value used in the interpretation of results.

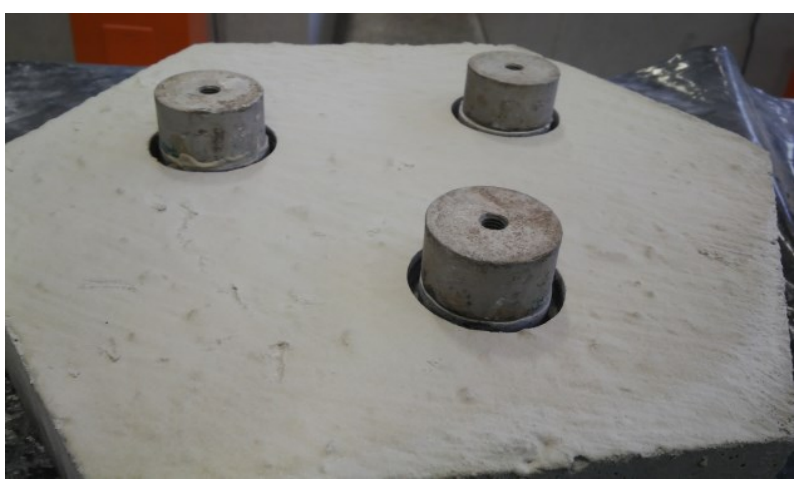

Figure 4: Test dollies glued to the isolated test areas.

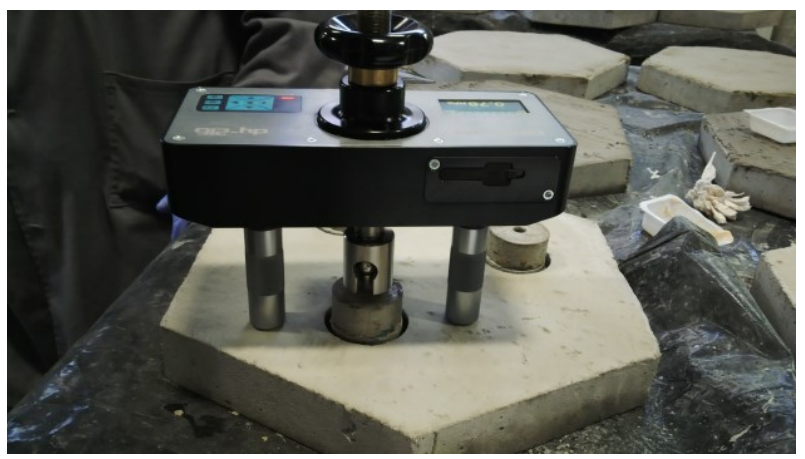

Figure 5: Test set-up, using a Proceq DY-216

\section{Test results}

The results of the pull-off testing are shown in Figures 6 and 7.

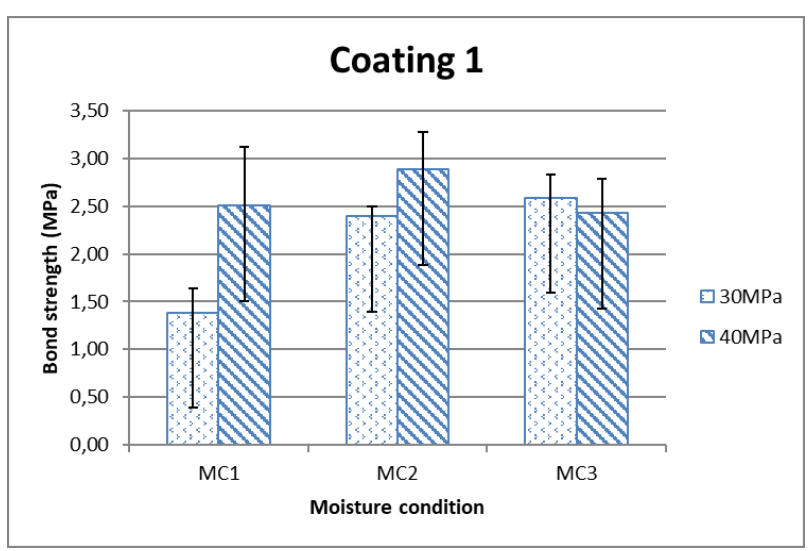

Figure 6: Coating 1, average tensile bond strength and STDV

The obtained failure modes for all tests are summarized in Table 2. None of the specimens failed at the interface between concrete substrate and coating. Most samples failed either in the substrate or inside the coating, with a few samples also showing partial failure between the coating the adhesive to the dolly. In cases of substrate failure, the full cohesive and adhesive potential of the coating materials could not be identified, i.e. the test results are a lower-bound indication of the coating's tensile pull-off strength. Typical failure modes are shown in Figures 8 and 9. 


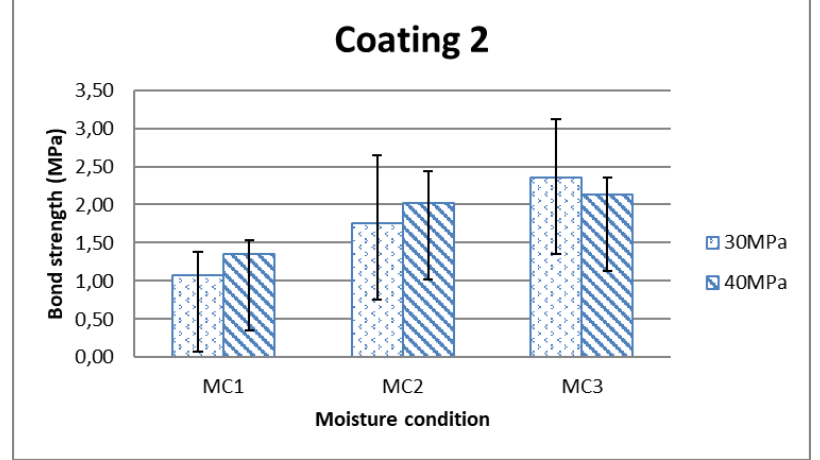

Figure 7: Coating 2, average tensile bond strengths and STDV

Table 2: Failure modes (A: cohesion failure in the substrate, B: cohesion failure in the coating, $\mathrm{C}$ : cohesion failure in the adhesive layer)

\begin{tabular}{|c|c|c|c|c|}
\hline Coating & \multicolumn{2}{|c|}{ Coating 1 } & \multicolumn{2}{c|}{ Coating 2 } \\
\hline Substr. & $30 \mathrm{MPa}$ & $40 \mathrm{MPa}$ & $30 \mathrm{MPa}$ & $40 \mathrm{MPa}$ \\
\hline \multirow{3}{*}{$\mathrm{MC1}$} & $\mathrm{B}$ & $\mathrm{A}$ & $\mathrm{B}$ & $\mathrm{B}$ \\
\cline { 2 - 5 } & $\mathrm{A}$ & $\mathrm{A}$ & $\mathrm{B}$ & $\mathrm{B}$ \\
\cline { 2 - 5 } & $\mathrm{B} / \mathrm{C}$ & $\mathrm{B}$ & $\mathrm{B}$ & $\mathrm{B}$ \\
\hline \multirow{3}{*}{$\mathrm{MC} 2$} & $\mathrm{~A}$ & $\mathrm{~A}$ & $\mathrm{~B} / \mathrm{C}$ & $\mathrm{B}$ \\
\cline { 2 - 5 } & $\mathrm{A}$ & $\mathrm{A}$ & $\mathrm{B}$ & $\mathrm{B}$ \\
\cline { 2 - 5 } & $\mathrm{A}$ & $\mathrm{A}$ & $\mathrm{B}$ & $\mathrm{B}$ \\
\hline \multirow{3}{*}{$\mathrm{MC} 3$} & $\mathrm{~A}$ & $\mathrm{~A}$ & $\mathrm{~A}$ & $\mathrm{~A}$ \\
\cline { 2 - 5 } & $\mathrm{A}$ & $\mathrm{A}$ & $\mathrm{A}$ & $\mathrm{A}$ \\
\cline { 2 - 5 } & $\mathrm{A} / \mathrm{B}$ & $\mathrm{A}$ & $\mathrm{A}$ & $\mathrm{A} / \mathrm{B}$ \\
\hline
\end{tabular}

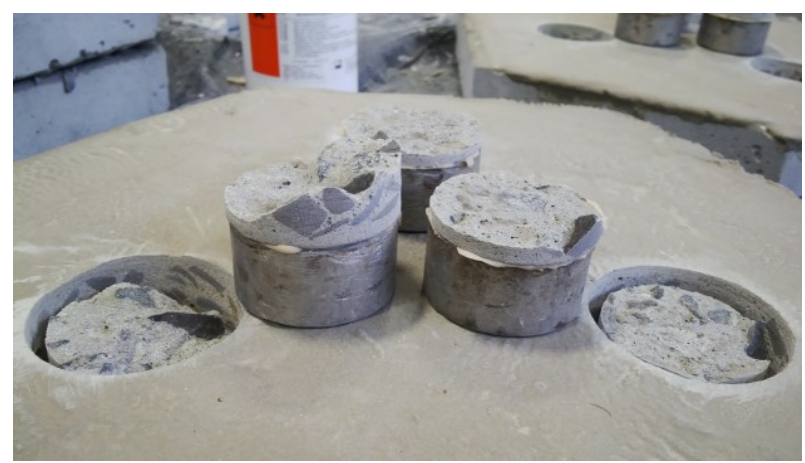

Figure 8: Typical failure mode in the substrate

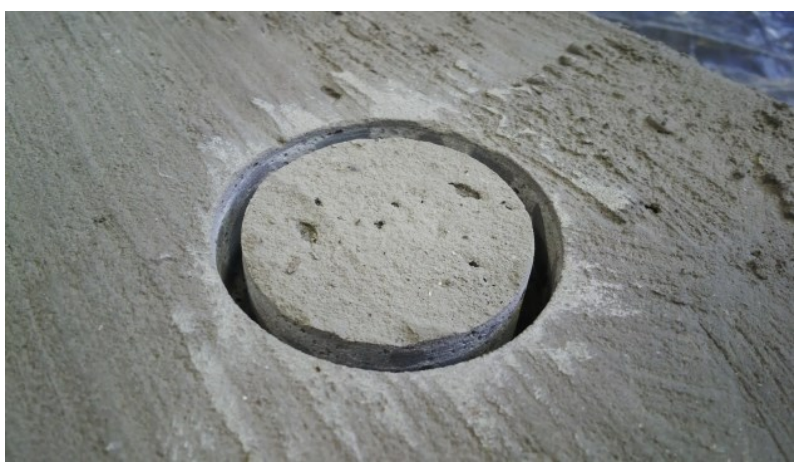

Figure 9: Typical failure in the coating

\section{Discussion}

\subsection{Influence of substrate compressive strength}

The results shown in Figures 6 and 7 suggest that, generally, higher bond strength values were obtained on the $40 \mathrm{MPa}$ substrates, compared to $30 \mathrm{MPa}$ substrates. However, a statistical analysis using the t-test indicates that the difference in bond strength was insignificant, except for Coating $1 / \mathrm{MC} 1$. It needs to be noted that the 2 substrate concretes had a similar strength (30 and 40 $\mathrm{MPa}$ ) and a wider range of tensile pull-off results might have been measured if a wider range of substrate strengths had been used, especially in the case where substrate failure was observed.

\subsection{Influence of substrate moisture condition}

The test results show a general trend of increasing pulloff strength with increasing substrate moisture content. For half of the direct parameter comparisons, the difference in pull-off strength with regards to substrate moisture condition was statistically significant (Coating 1, $30 \mathrm{MPa}$ : MC1 vs. MC2; Coating 2, $30 \mathrm{MPa}$ MC1 vs. MC2 vs. MC3, 40 MPa: MC1 vs. MC2).

The results suggest that the provision of the commonly specified substrate moisture condition does in fact have a positive effect on the performance of the coating, while a dry substrate concrete is detrimental to the performance. The reasons for this were not investigated in more detail, but the most logical explanation is that dry substrates absorb fluids from the coating, which then results in a lower degree of chemical reaction between the constituents of the coating. In the case of cementitious coatings, this refers to moisture loss from the coating and related reduction in the formation of hydration products.

Overall, an increasing amount of substrate failure, as opposed to coating cohesion failure, was observed with increasing substrate moisture condition. This, too, indicates that dry substrates extract moisture from the coatings, which results in a reduction of the coating's cohesion strength. 


\subsection{Failure modes and test results in general}

The composite specimens with Coating 1 generally had high pull-off strengths of around $2.5 \mathrm{MPa}$, which to the experience of the authors are very good values. In most cases, the failure mode was that of substrate cohesion failure, indicating that the actual interface bond and coating cohesion strengths were higher than the measured values. Coating 1 did not only achieve the highest bond strength in general but was also the least affected by the substrate moisture condition, indicating its robustness.

With Coating 2, pull-off strengths of around $2-2.5$ MPa were achieved on the substrate that was prepared according to the product specifications. In addition, the failure mode observed for MC3 was that of substrate cohesion failure. The performance of Coatings 1 and 2 was therefore very similar, provided the substrate was prepared according to the specifications.

\section{Conclusions}

The coatings tested showed excellent pull-off test results on properly prepared substrate concretes. Proper substrate preparation included sandblasting the concrete to remove surface laitance and provide a clean and slightly rough interface, as well as providing a saturated, surface-dry interface at the time of coating application. A general trend of decreasing pull-off strength with decreasing substrate moisture condition was observed, highlighting the importance of adhering to the installation guidelines specified by material suppliers. Dry substrates absorb moisture from the coatings, which results in a lower degree of hydration in cementitious coatings.

\section{References}

[1] Bassi, R and Roy, SK. 2002. Handbook of coatings for concrete. Scotland, UK. ISBN 1-870325-82-6. 12-190.

[2] Basham, K. 1998. Preparing surfaces for coatings, a checklist for avoiding failures of decorative and protective coatings. Publication \#C980525.

[3] ACI international, BRE, concrete society, international concrete repair institute (ICRI). 2003. Concrete repair manual, second edition: volume 1use of epoxy compounds with concrete, 874-885, and volume 2- surface treatments for protection and enhancement of concrete, 1458-1546.

[4] American society for testing and materials (ASTM). 2002. Standard practice for surface cleaning concrete for coating. Designation: D 4258-83. West Conshohocken, PA

[5] American society for testing and materials (ASTM). 1999 (reapproved). Standard practice for abrading concrete. Designation: D 4259-88. West Conshohocken, PA.

[6] Allied Construction Technologies (A.C.Tech). n.d. Technical Bulletin;1. Substrate Requirements, Compressive and Cohesive Testing.

[7] Benn, BT. 2008. The influence of curing and surface preparation on the adhesion of protective coatings on concrete. University of the Witwatersrand. Johannesburg, SA.

[8] Sika Group. 2004 and 2012. Solutions/product datasheets. Switzerland. Available: http://www.sika.com.

[9] Vicroads, 2013. Test method: Determination of the Tensile Bond Strength of Concrete repairs and Strengthening systems. RC 252.02. State government Victoria. 